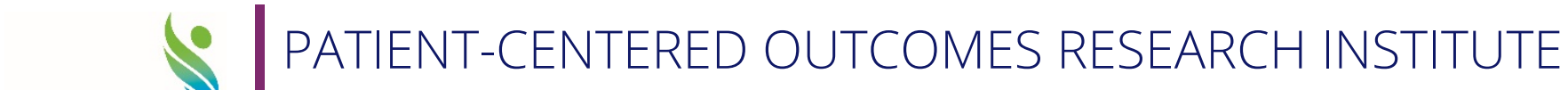 pcori ?. RESEARCH SUMMARY
}

\section{Examining the Effectiveness of Case Management Programs on Preventing Hospital Stays in Older Adults with Multiple Chronic Health Problems -- A PCORnet ${ }^{\circledR}$ Study}

Principal investigator

Maureen A. Smith, MD, PhD, MPH
Organization

University of Wisconsin-Madison

\section{What was the research about?}

When older adults have more than one long-term, or chronic, health problem, their health care may be hard to manage. Case managers-nurses or social workers who help manage a patient's care-may be able to help. If their care is managed well, patients may be able to stay healthy and avoid going to the emergency room, or ER, or hospital.

In this study, the research team wanted to find out if having help from case managers kept patients with chronic health problems from going to the ER or hospital. The team compared patients with and without case managers.

\section{What were the results?}

A year after patients started getting help from case managers, patients with and without case managers didn't differ in the number of ER visits or days they stayed in the hospital.

\section{Who was in the study?}

The study included electronic health record data from 5,768 patients receiving care at two Medicare accountable care organizations, or ACOs. ACOs are groups of healthcare providers, such as doctors and hospitals, who work together to provide patient care. Of these patients, 88 percent were White, and
12 percent were other races. The average age was 71 , and 57 percent were women. More than 90 percent of patients had three or more chronic health problems, like diabetes.

\section{What did the research team do?}

The research team linked electronic health records from the ACOs with Medicare claims from January 2011 through September 2015. The team identified records for patients who were enrolled in a case management program. In the program, a nurse or social worker managed patients' care. They also called patients twice a month to check on their needs.

Based on patient traits in the records, such as type of health problem, the research team matched patients who were enrolled in the case management program with patients who weren't. Then they compared the patients who were in the program with those who weren't. The team looked at the number of ER visits and days patients spent in the hospital one year after they started the program.

Patients, health system administrators, and doctors provided input on the study design and analysis. 


\section{What were the limits of the study?}

The research team only looked at data from patients for one year after starting the program. Results may differ if the team looked at data for longer than one year.

Future research could look at other ways to support patients with chronic health problems.

\section{How can people use the results?}

ACOs can use these results when considering ways to help patients with chronic health problems manage their care.

To learn more about this project, visit www.pcori.org/Smith023.

The PCORnet ${ }^{\circledR}$ Study reported in this results summary was conducted using PCORnet ${ }^{\circledR}$, the National Patient-Centered Clinical Research Network. PCORnet ${ }^{\circledR}$ is intended to improve the nation's capacity to conduct health research, particularly comparative effectiveness research (CER), efficiently by creating a large, highly representative network for conducting clinical outcomes research. PCORnet ${ }^{\circledR}$ has been developed with funding from the Patient-Centered Outcomes Research Institute ${ }^{\circledR}\left(\right.$ PCORI $\left.^{\circledR}\right)$. 